\title{
Catatan awal tentang Logika Sentensial dan implikasinya dalam diskusi Manunggaling Kawula Gusti dan Trinitas
}

\author{
Victor Christianto
}

\begin{abstract}
Abstrak
Dalam catatan awal ini kami mengajukan argumen bahwa konsep logika sentensial memuat kemungkinan betweenness/neitherness/ bothness yang tidak dikenal dalam logika biner Aristotelian. Kami mengusulkan bahwa konsep logika sentensial akan berguna untuk menjembatani dialog antara pendukung nondualisme seperti mistisisme kaum sufi dan para pendukung mazhab dualisme. Dalam konteks ini, kekristenan menawarkan kerangka berpikir bahwa hanya Yesuslah satu-satunya Sang Manunggaling Kawula Gusti yang sejati, sementara kita sebagai manusia dapat berperan sekaligus sebagai makhluk yang berbeda dengan Sang Gusti, namun pada saat yang sama, umat percaya menyatu dengan Tuhan, meski bukan dengan konsep manunggalnya para sufi. Artinya, logika sentensial/ proposisional memungkinkan kita memahami bahwa manusia serempak disatukan dengan Sang Khalik, namun pada saat yang sama tetap berbeda dengan Sang Khalik. Artinya non-dualisme dan dualisme pada saat yang sama. Tentunya diperlukan kajian yang lebih mendalam mengenai topik ini, yang akan kami tuliskan dalam artikel lain kemudian.
\end{abstract}

\begin{abstract}
In this introductory exploration, we argue that the concept of sentential logic contains a possibility of betweenness / neitherness / bothness unknown to Aristotelian binary logic. We propose that the concept of sentential logic will be useful for bridging the dialogue between supporters of non-dualism such as the mysticism of the Sufis and the supporters of the dualism schools. In this context, Christianity offers a framework of thinking that only Jesus is the true Manunggaling Kawula Gusti, while we humans can simultaneously act as creatures that are different from the Gusti (God), but at the same time, believers are one with God, although not the same with the concept of divine unity of the Sufis. That is, sentential / propositional logic makes it possible that humans are simultaneously united with the Creator, but at the same time remain different from the Creator. It means non-dualism and dualism at the same time. For sure, a more in-depth exploration is required, and we plan to present it in another article.
\end{abstract}

\section{Pendahuluan}

Ijinkan penulis memulai artikel ini dengan suatu kutipan dari artikel salah satu dari penulis (RIC), yang menyatakan:

"Modern major religions in Indonesia that originated outside Asia might find language, pattern of thought, or metaphore used by Javanese spiritual or mystical texts to be forbidding. Yet, in the past many spiritual writers or editors have used in the same expression or literary pattern such as in the form of the Ecclesiasties and other Wisdom 
Literatures that used dialectical pattern of thought or hidden teaching. In the Sufi circle, such as in the work of Ibnu Al Arabi or Al Ghazali, hidden teaching is placed underneath many statements. Failure to appreciate and study the folk religion or Kejawen spiritual texts might have root in the view of the European who encountered it in the last century such as Kramer (Zoetmulder, 1991:348). They failed to distinguish them from superstitious belief, animism, prophetic text, and the like. However, after 1981 when Christian leaders in the world started to delve into more holistic Pneumatologi, there are some openness to hear more closely the spirit of the folk religions (Kärkkäinen, 2014) and then, their texts." (Chandra 2020)

Salah satu masalah dalam memahami unio mystica adalah, bahwa unio mystica sendiri ada kepelbagaian, dari lebur sampai communion (atau disebut divine communion), tapi pendekatan pola pikir itu yang kiranya tepat. Karena mungkin cara pendekatan dualistis atau biner tidak cocok menjelaskan ontologi dan metafisika. Harus sentential atau malah bukan semua tapi pendekatan metaphor dan alegori. Jadi dalam artikel ini, kami mau fokus pada membahas konsep manunggaling di jawa, dibanding unio mystica yang berkembang pada kalangan Barat mistis, dan kesimpulan sementara kami adalah bahwa keduanya tidak tepat kalau dibaca dengan kerangka either or.

Dalam konteks diskusi dalam sufisme, Manunggaling Kawula Gusti menjadi mungkin, jika kita memahami makna logika non-dualisme. Namun dalam tulisan ini, kami mengusulkan logika sentensial/proposisional.

Merujuk pada Gadamer sebagai dipaparkan oleh Darmaji, ${ }^{255}$ dialog antar iman atau keyakinan berguna untuk mengembangkan cakrawala pemikiran (horizon), maka tujuan penulisan ini adalah memperkaya proses dialog dengan meningkatkan pemahaman akan corak logika yang dipakai masing-masing pihak yang berdialog. Dengan cara menjelaskan logika sentensial, diharapkan artikel ini dapat memperluas horizon pemikiran, baik bagi teolog yang berusaha melakukan dialog iman untuk memahami mitra dialog dan menyeberangkan gagasan tentang Yesus Sang Mesias kepada umat di Nusantara, maupun para penganut Kejawen yang berusaha membagikan pemahaman dan pengalaman spiritual mereka.

\footnotetext{
${ }^{255}$ Agus Darmaji. Dasar-Dasar Ontologis Pemahaman Hermeneutik Hans-Georg Gadamer. Refeksi, Volume 13, Nomor 4, April 2013, hal. 469-494.
} 


\section{Definisi logika sentensial}

Apakah yang dimaksud dengan logika sentensial? Logika sentensial atau juga dikenal dengan nama Propositional Logic adalah salah satu cabang logika yang mengkaji cara menghubungkan atau memodifikasi suatu proposisi, pernyataan, atau kalimat untuk membentuk proposisi, pernyataan atau kalimat yang lebih rumit serta juga hubungan nalar dan sifatnya yang lebih utuh akibat penggabungan karakteristik dan sifat-sifat sebagai hasil dari metode penggabungan atau perubahan tersebut ${ }^{256}$. Tujuan logika ini adalah menguji atau menyatakan kebenaran yang dimuat dalam suatu proposisi atau pernyataan dan kalimat. Cara menggunakan logika ini adalah dengan menggunakan simbol-simbol sehingga memiliki sintaks sendiri257.

\section{Asal usul Logika sentensial258}

Sentential Logic dibuat pada tahun 225 SM. oleh ahli logika Yunani kuno Chrysippus. Pengetahuan tentang logika itu hilang pada Abad Kegelapan, tetapi ditemukan kembali oleh filsuf Prancis Abelard pada abad ke-12. Sistem tabel kebenaran untuk Sentential Logic ditemukan pada tahun 1902 oleh ahli logika Amerika Charles Peirce untuk menampilkan bagaimana kebenaran dari beberapa kalimat akan mempengaruhi kebenaran kalimat lainnya. Tabel kebenaran ditemukan kembali secara independen oleh Ludwig Wittgenstein dan Emil Post.

Sistem pembuktian untuk Logika Sentensial dikembangkan pada tahun 1879 oleh ahli logika Jerman Gottlob Frege untuk memungkinkan membuat pembuktian yang serupa dengan pembuktian dalam geometri bidang ketika aturan kesimpulan dan aksioma digunakan. Bukti adalah daftar pernyataan/kalimat, urutan langkah.

Sistem pembuktian untuk Logika Sentensial sering disebut Sentential Calculus. Jika Sentential Logic menggunakan nama Propositional Logic, maka sistem pembuktiannya disebut Propositional Calculus.

\footnotetext{
${ }^{256}$ Internet Encyclopaedia of Philosophy: a Peer Review Academic Resource: Propositional Logic https://iep.utm.edu/prop-log/

${ }^{257}$ Daniel J. Velleman, "Sentential Logic," in How to Prove It (Cambridge, UK: Cambridge University Press, 2011), hal . 8-54, https://doi.org/10.1017/cbo9780511808234.003.

${ }^{258}$ Bradley H. Dowden. Diakses dari sumber Internet. url: https://human.libretexts.org/Bookshelves/Philosophy/Book\%3A_Logical_Reasoning_(Dowden)/11\%3A_Logic al_Form_and_Sentential_Logic/11.04\%3A_Sentential_Logic/11.4.04\%3A_History_of_Sentential_Logic
} 
Logika Sentensial juga memiliki properti kebalikannya, yaitu setiap argumen yang dapat dibuktikan juga valid. Jadi, validitas dan pembuktian datang pada hal yang sama dalam arti himpunan argumen yang valid juga merupakan himpunan argumen yang kesimpulannya dapat dibuktikan dari premis-premisnya.

\section{Betweenness dan neither/nor}

Kerangka berpikir orang Jawa secara umum banyak dipengaruhi oleh prinsip nondualisme atau kadang disebut pradnja paramita. Salah satu ciri dari logika tersebut adalah adanya ruang bagi neither/nor, misalnya yang kita jumpai dalam ungkapan: "ora kena kinaya ngapa" (terj: tidak dapat disamakan dengan apapun), atau misalnya juga ungkapan khas : "ngono yo ngono nanging ojo ngono" (terj.: begitu ya begitu namun jangan begitu.) Demikian pula, ungkapan ekonomi Pancasila sering dirumuskan dalam logika bukan ini/bukan itu.

Meski pada umumnya, ungkapan tersebut dihubungkan dengan konsep Memayu hayuning Bawana, namun pada artikel ini kami mencoba melihat dari perspektif logika, yakni logika sentensial.

Dalam artikel ini, kami mengajukan argumen bahwa konsep logika sentensial memuat kemungkinan betweenness/neitherness/bothness yang mungkin berbeda dalam logika biner Aristotelian. Kami mengusulkan bahwa konsep logika sentensial akan berguna untuk menjembatani dialog antara pendukung non-dualisme seperti mistisisme kaum sufi dan para pendukung mazhab dualisme.

Dalam ungkapan logika proposisional/sentensial, maka ada suatu teorem yang disebut Aturan De Morgan, sebagai berikut: "Komplemen dari gabungan dua set sama dengan perpotongan komplemennya dan komplemen dari perpotongan dua set sama dengan gabungan komplemennya. Ini disebut hukum De Morgan." ${ }^{259}$ Atau dalam notasi simbolik:

For any two finite sets A and B; 260

(i) $(A \text { U B })^{\prime}=A^{\prime} \cap B^{\prime}$ (which is a De Morgan's law of union).

(ii) $(A \cap B)^{\prime}=A^{\prime} U B^{\prime}$ (which is a De Morgan's law of intersection).

\footnotetext{
259 https://www.math-only-math.com/proof-of-de-morgans-law.html ${ }^{260} \mathrm{https}: / /$ www.math-only-math.com/proof-of-de-morgans-law.html
} 
Selanjutnya, pernyataan neither/nor dapat ditulis: "Hukum De Morgan adalah kunci untuk memahami pernyataan "bukan / atau". Hukum tersebut mungkin terlihat sedikit menakutkan, tetapi mereka memiliki interpretasi yang cukup alami. Pernyataan dalam bentuk "Baik P maupun Q" bisa sedikit rumit untuk dikerjakan, karena kalimat alami tidak dibentuk begitu saja. Namun, "Baik P maupun Q" tidak dapat diartikan ulang sebagai "Ini bukan kasus P, dan bukan kasus QC yang menyatakan bahwa P dan Q salah sama dengan mengklaim bahwa tidak ada yang benar. Ini dapat dirumuskan kembali sebagai "Bukan kasus bahwa setidaknya satu dari P dan Q adalah benar", yang merupakan penyangkalan dari "Setidaknya satu dari P dan Q adalah benar" - dalam simbol, " (PVQ)". Ini adalah salah satu hukum De Morgan, dan juga dapat diverifikasi dengan tabel kebenaranAda alasan serupa di balik hukum lain, yang menyatakan bahwa " P V Q" setara dengan " (P \& Q)".

Meski sepintas, tampaknya proposisi neither/nor tidak berkontradiksi dengan logika biner Aristotelian, namun sebenarnya ini melibatkan konsep yang jauh lebih rumit. Lihat misalnya Heald:

"It is widely accepted that "neither true nor false" can be regarded as the third logic state. Many systems, however, have erroneously assigned the "don't know" state to "neither true nor false". This error can be found in the writings of Aristotle and Jan Lukasiewicz regarding future contingents and follow through to Dempster-Shafer theory and Zaitsev's useful eight valued logics."

Dalam konteks ini, kekristenan menawarkan kerangka berpikir bahwa hanya Yesuslah satu-satunya Sang Manunggaling Kawula Gusti yang sejati, sementara kita sebagai manusia dapat berperan sekaligus sebagai makhluk yang berbeda dengan Sang Gusti, namun pada saat yang sama, umat percaya menyatu dengan Tuhan, meski bukan dengan konsep manunggal seperti yang dipahami oleh para sufi. Artinya, logika sentensial/proposisional memungkinkan bahwa manusia serempak disatukan dengan Sang Khalik, namun pada saat yang sama tetap berbeda dengan Sang Khalik. Artinya nondualisme dan dualisme pada saat yang sama.

Dalam konteks itu, penulis sependapat dengan Noorsena (Noorsena 2003), bahwa iman Kristen memercayai Yesus sebagai Sang Manunggaling Kawula Gusti yang sejati. Dalam hal ini, kita semua sebagai umat Kristen memiliki perantara yang sempurna kepada Bapa (bdk. Surat Ibrani). Artinya, dalam Kristus kita semua sekaligus menyatu 
namun juga berbeda dengan Sang Khalik. Yang dapat menyatu sempurna dengan Sang Khalik hanyalah Yesus Kristus, Sang Kalimatullah.

Paralel tersebut dapat dilukiskan sebagai berikut dalam kerangka berpikir logika sentensial:

Identitas A $\rightarrow$ neitherness/betweenness/bothness $\rightarrow$ identitas B

identitas kawula $\rightarrow$ Sang Manunggaling Kawula Gusti (Yesus Kristus) $\rightarrow$ identitas Gusti

Demikian pula, kita dapat melihat dari perspektif ini, mengenai logika dari Manunggaling kawula Gusti. Kalau pengamatan sepintas kami, salah stu sumber perbedaan pendapat antara pengikut Siti Jenar dan Walisongo, adalah karena logika dualisme: bisa dijembatani dengan betweenness/neitherness, misalnya: $<\mathrm{A}>$ dualitas kawula-Gusti, $<\mathrm{B}>$ non-dualitas antara kawula-Gusti.

Maka pandangan Kristen adalah sekaligus dualitas dan sekaligus manunggal, karena hanya Yesuslah Sang Manunggaling Kawula Gusti yang sejati. Atau dalam notasi: " (A \& B)".

Jadi antara:

$<\mathrm{A}>\rightarrow$ betweenness/neitherness $\rightarrow<\mathrm{B}>$.

\section{Diskusi seputar Trinitas}

Trinitas merupakan suatu topik yang sangat rumit untuk dipahami, dan memang tidaklah mungkin menjelaskan Allah Tritunggal secara tuntas - entah itu oleh orang awam maupun teolog kawakan-, karena senantiasa ada unsur misteri ilahi karena memang Tuhan berada di luar jangkauan rasio kita (supra-rasional).

Seperti dibahas dalam salah satu buku yang membahas topik Trinitas,: The Trinity among the Nations, yang diedit oleh Green, Pardue \& Yeo (Green et al, 2017). Dalam bab 6 buku ini, Natee Tanchanpongs, berupaya memberikan suatu ringkasan dari pemikiran 4 teolog termasuk Pannikar, Jung Young Lee (Korea), Brahmabandhab Upadhyaya (India), dan 
Nozomu Miyahira dari Jepang. Patut dicatat bahwa teolog Upadhyaya yang mengembangkan kontekstualisasi Trinitas dari pendekatan logika advaita (nondualisme) juga mesti dikaji secara berhati-hati.

Dengan kata lain, salah satu upaya untuk menjembatani filsafat dualisme yang khas dari logika biner ala Aristotelianisme, adalah menemukan titik tengahnya terhadap logika advaita (non-dualisme). Dalam hal ini, logika sentensialisme mungkin dapat membantu menjernihkan persoalan tersebut.

Dalam hubungan ini, Trinitas dapat dijembatani dengan logika neither/nor tersebut:

$<$ A $>$ individualitas dalam Trinitas $\rightarrow$ betweenness/neitherness $\rightarrow<B>$ leburnya tiap individu dalam Trinitas (oneness).

Demikian kira-kira kalau mau dibahas dalam perspektif logika. Lalu bagaimana pengertian individualitas yang lebur tersebut?

Jika kita hendak memahami individualitas dalam Trinitas yang bersifat "diskresi non-separasi", artinya dapat dibedakan namun tidak terpisahkan, mungkin akan menolong jika kita menggunakan metafora kelopak bunga mawar. Dalam metafora tersebut, setiap kelopak mawar adalah entitas yang berbeda namun sekaligus menyatu dengan bunga mawar sebagai satu kesatuan. Semoga metafora tersebut sedikit menolong memahami gagasan diskresi non-separasi.

Ijinkan kami mengusulkan sebuah metafora yang lain, meski metafora berikut sebenarnya juga jauh dari sempurna, namun ada baiknya kami kemukakan untuk menolong pembaca memahami. Dalam gramatika bahasa Inggris, dikenal katabenda yang bisa dihitung secara aritmetik $(1,2,3)$, misalnya apple, orange dst. Disebut sebagai countable noun. Dan ada juga katabenda yang tidak dapat dihitung (uncountable noun), misalnya air (water), dst. Maka kita tidak dapat mengatakan "I drink a water." Namun, kita mengatakan “I drink a glass of water." Demikian pula, dikenal "I drink a cup of coffee."

Demikian pula, Tuhan adalah Esa yang bukan countable, karena Dia meliputi segala hal di jagad raya ini. Sebagaimana Rasul Paulus menyatakan dalam pidatonya di Athena: 
"Sebab di dalam Dia kita hidup, kita bergerak, kita ada, seperti yang telah juga dikatakan oleh pujangga-pujanggamu: Sebab kita ini dari keturunan Allah juga." (Kis. $17: 28)$

Karena itu, tentu menjadi keliru jika kita menerapkan logika aritmetik 1+1+1=3 untuk menjelaskan Tuhan, Yang Maha Esa. Demikian pula kata "Esa" dalam Ulangan 6:4 sebenarnya ditransliterasikan dari kata Echad (satu yang mewakili wholeness, artinya uncountable), bukan Yachid (satu yang aritmetik/countable). Bandingkan Botterweck \& Ringgren (1970-1974).

“Dengarlah, hai orang Israel: TUHAN itu Allah kita, TUHAN itu esa!” (Ul. 6:4)

Jika kita dapat menerima makna Esa atau Echad yang uncountable tersebut, maka kita akan lebih mudah untuk menerima kebenaran bahwa Tuhan adalah Dia yang meliputi segala hal, Dia yang sekaligus Tunggal dan Jamak. Itulah Trinitas.

Sebagai catatan penutup, penulis mendengar bahwa di Jawa Tengah sudah ada gereja Hyang Triniji Suci di Ngaliyan, Bejen, Ngaliyan, Temanggung, Kabupaten Temanggung. Pemikiran tentang Sang Hyang Triniji Suci dapat menjadi salah satu cara yang khas budaya lokal (baca: Jawa) dalam menyeberangkan gagasan tentang Trinitas.

Kami berharap pemaparan yang serba singkat ini berguna untuk kajian selanjutnya.

\section{Penutup}

Demikianlah sekelumit catatan singkat yang masih merupakan pemikiran awal dan tentunya jauh dari memadai, namun kiranya diskusi dari perspektif logika ini berguna bagi kajian-kajian seputar Trinitas maupun Manuggaling Kawula Gusti dalam terang iman Kristen yang lebih lengkap.

Apa yang hendak disampaikan dalam tulisan singkat ini adalah logika sentensial/proposisional memungkinkan kita memahami bahwa manusia serempak disatukan dengan Sang Khalik, namun pada saat yang sama tetap berbeda dengan Sang Khalik. Artinya non-dualisme dan dualisme pada saat yang sama. Tentunya diperlukan kajian yang lebih mendalam mengenai topik ini, yang akan kami tuliskan dalam artikel lain kemudian. 
Tulisan di atas merupakan bagian dari upaya memformulasikan logika yang khas Nusantara, khususnya dalam memahami konsep Manunggaling Kawula Gusti dll. 


\section{Kepustakaan}

Bahm, A.J. Filsafat Perbandingan. Yogyakarta: Penerbit Kanisius, 2003.

Benthem, Johan van, Hans van Ditmarsch, Jan van Eijck, Jan Jaspars. Logic in action. Nov. 2016.

Botterweck, G.J. \& H. Ringgren. "Echadh" in Theological dictionary of the Old Testament. Rev. ed. Stuttgart: Verlag W. Kohlhammer GmbH, 1970-1974, p. 173

Chandra, R.I. The Complexity of Serat Jatimurti: Uncovering Its Teaching about Reality and Human Nature. Unpublished draft, 2020.

Green, G.L., Stephen T. Pardue, K.K. Yeo. The Trinity among the Nations: The Doctrine of God in the Majority World. London: Langham Global Library, 2017.

Heald, G. Why the logic state 'neither true nor false' has been incorrectly assigned.

url:

https://www.researchgate.net/publication/319328333_Why_the_logic_state_\%27neither_true_ nor_false\%27_has_been_incorrectly_assigned

Noorsena, B. Kanjeng Gusti Isa, Kalimatullah, Sang Manunggaling Kawula Gusti. Dikutip dari buku Menyongsong datangnya Ratu Adil. Yogyakarta: Penerbit Andi Offset, 2003.

Susanto, H. Yesus Sebagai Anak Allah Menurut Injil Matius dan Implementasinya Dalam Berapologetika. LOGIA, vol. 1, no. 1 (2019).

Tertullian. "Adversus Praxean" in Tertullian: Complete Works. Delphi Classics. (translated by Peter Holmes).

Zoetmulder, P.J. Manunggaling kawula Gusti. Jakarta: Gramedia, 1991

Sumber internet

Propositional Logic. url: https://iep.utm.edu/prop-log/

https://stackoverflow.com/questions/5201034/translating-neither-nor-into-a-mathematicallogical-expression

Tentang Penulis:

Victor Christianto menyelesaikan studi teologi (MTh.) di STT Satyabhakti, Malang. Kini mengajar di STT Satyabhakti - Jakarta, selain aktif meneliti dan mengelola beberapa situs, di antaranya adalah http://www.secondcominginstitute.com. Dapat dihubungi melalui email: victorchristianto@gmail.com 